\title{
Microwave Properties of RE(Nd, Tb)FeCoB Alloy System
}

\author{
Pan Shunkang, Lin Peihao, Wang Lei, Liu Xing, Hu Shiqi, Zhou Huaiying
}

Guilin University of Electronic Science and Technology, Guilin 541004, China

\begin{abstract}
The $\mathrm{RE}(\mathrm{Nd}, \mathrm{Tb}) \mathrm{FeCoB}$ magnetic powders were prepared by arc melting, high energy ball milling and a partial oxidation treatment method. A X-ray diffraction device and a vector network analyzer were used to analyze the phase structure and microwave absorbing properties of the powders. The results of $\mathrm{B}$ addition to the microwave absorbing performances in the $\mathrm{NdFeCo}$ alloy, indicate that $\mathrm{Nd}_{2} \mathrm{Fe}_{14} \mathrm{~B}$ phase will precipitate and the relative content of the $\alpha$-Fe phase increases with the increasing of $\mathrm{B}$ in $\mathrm{Nd}_{10.53} \mathrm{Fe}_{77.84} \mathrm{Co}_{11.63}$ alloy powder. When $\mathrm{Nd}$ is replaced by the heavy rare earth $\mathrm{Tb}$ in $\mathrm{NdFeCoB}$ alloy, the powders consist of $\alpha$ - $\mathrm{Fe}$, $\mathrm{Tb}_{2} \mathrm{Fe}_{14} \mathrm{~B}, \mathrm{~Tb}_{2} \mathrm{Fe}_{17}$ and a small amount of $\mathrm{Tb}_{2} \mathrm{O}_{3}$ phases. $\left(\mathrm{Nd}_{10.53} \mathrm{Fe}_{77.84} \mathrm{Co}_{11.63}\right)_{97} \mathrm{~B}_{3}$ powder has a minimum of absorption peak frequency, which is $-9.5 \mathrm{~dB}$ at $4.5 \mathrm{GHz}$. After substituting $\mathrm{Tb}$ for $\mathrm{Nb}$ in $\left(\mathrm{Nd}_{10.53} \mathrm{Fe}_{77.84} \mathrm{Co}_{11.63}\right)_{97} \mathrm{~B}_{3}$ alloy the absorption peak frequency increases to $6.3 \mathrm{GHz}$, but the reflectivity value is reduced to $-11 \mathrm{~dB}$.
\end{abstract}

Key words: $\mathrm{NdFeCoB}$ alloy; microwave absorption properties; microstructure; high energy ball milling

The application of electromagnetic technology can create the material civilization, but at the same time it brings people into a world full of electromagnetic radiation. The electromagnetic wave radiation emission from the working electronic instruments, not only interfere the normal work of other electronic instruments, but also threat the health of human body ${ }^{[1-3]}$. A lot of research work have been done to reduce the harm of the electromagnetic radiation, and people find that using of magnetic absorbing materials to guide the electromagnetic wave is a good idea. Through the resonance, a large number of the electromagnetic wave radiation energy can be absorbed. Coupling the electromagnetic wave energy into heat energy is a very good way to inhibit and interfere electromagnetic wave radiation. Generally, the working frequency band of the mobile communication, the electronic equipment, and radar systems are in the range of about 1 6 $\mathrm{GHz}$, but so far the absorption peak frequencies of the majority absorbing materials are above $6 \mathrm{GHz}$ when the absorbing layer thickness less than $2 \mathrm{~mm}^{[4-7]}$. So researching the absorbing materials with thin thickness and low absorption peak frequency becomes one of today's hotspots. In this work, $\mathrm{Nd}_{2}(\mathrm{Fe}, \mathrm{Co})_{17}$ alloy was used as the basic material. With the purpose of reducing material absorption peak frequency, B element was added into the alloy to change the phase structure, and then heavy rare earth $\mathrm{Tb}$ was used to replace light rare earth $\mathrm{Nd}$ to explore the effect on the phase structure and microwave absorbing properties.

\section{Experiment}

The $\left(\mathrm{Nd}_{10.53} \mathrm{Fe}_{77.84} \mathrm{Co}_{11.63}\right)_{100-x} \mathrm{~B}_{x} \quad(x=0, \quad 1, \quad 3, \quad 5$, mole fraction, \%) samples were prepared by $\mathrm{Fe}, \mathrm{Co}, \mathrm{Nd}, \mathrm{Tb}$ (purity not less than $99.50 \%$ ) and Fe-B alloy. They were smelted in a vacuum arc furnace under the protection of high purity argon $(99.99 \%)$, then the samples underwent a homogenization heat treatment at $1050{ }^{\circ} \mathrm{C}$ for $48 \mathrm{~h}$ under vacuum environment, and were milled $72 \mathrm{~h}$ under the protection of gasoline using planet ball mill (QM-1SP), whose speed was $250 \mathrm{r} / \mathrm{min}$. The mass ratio of the balls to the powers was $15: 1$. The powder underwent oxidation treatment at $100{ }^{\circ} \mathrm{C}$ for $2 \mathrm{~h}$ and the XRD device (D8 ADVANCE) was used for phase analysis. The well-prepared powders were mixed with paraffin in 4:1 ratio (mass ratio). The mixture was prepared into a coaxial ring with a thickness of $3.5 \mathrm{~mm}$, the inside and outside diameters of which were 3 and $7 \mathrm{~mm}$, respectively. The complex

\footnotetext{
Received date: April 21, 2013

Foundation item: National Natural Science Foundation of China (50961005); National Natural Science Foundation of Guangxi (2012GXNSFGA06002)

Corresponding author: Pan Shunkang, Ph. D., Professor, School of Materials Science and Engineering, Guilin University of Electronic Technology, Guilin 541004, P. R. China, Tel: 0086-773-2291434, E-mail: skpan88@163.com 
permeability and the complex permittivity in the frequency range of $2 \sim 18 \mathrm{GHz}$, which were used to calculate the reflectivity of the sample, were measured with HP8722ES microwave vector network analyzer.

\section{Results and Discussion}

\subsection{Effects of $B$ on the microwave absorbing performan- ces in NdFeCo alloy}

Fig. 1 is the XRD patterns of $\left(\mathrm{Nd}_{10.53} \mathrm{Fe}_{77.84} \mathrm{Co}_{11.63}\right)_{100-x} \mathrm{~B}_{x}$ $(x=0,1,3,5)$ powders. It is demonstrated that $\mathrm{Nd}_{10.53} \mathrm{Fe}_{77.84^{-}}$ $\mathrm{Co}_{11.63}$ powders are mainly composed of $\alpha-\mathrm{Fe}, \mathrm{Nd}_{2} \mathrm{Fe}_{17}$, a small amount of $\mathrm{Fe}_{2} \mathrm{Nd}$ and $\mathrm{Nd}_{2} \mathrm{O}_{3}$ phases, $\left(\mathrm{Nd}_{10.53} \mathrm{Fe}_{77.84} \mathrm{Co}_{11.63}\right)_{99} \mathrm{~B}$ powders mainly consist of $\alpha$ - $\mathrm{Fe}, \mathrm{Nd}_{2} \mathrm{Fe}_{17}$, a small amount of $\mathrm{Nd}_{2} \mathrm{Fe}_{14} \mathrm{~B}$ and $\mathrm{Nd}_{2} \mathrm{O}_{3}$ phases, $\left(\mathrm{Nd}_{10.53} \mathrm{Fe}_{77.84} \mathrm{Co}_{11.63}\right)_{97} \mathrm{~B}_{3}$ powders are mainly composed of $\alpha$ - $\mathrm{Fe}, \mathrm{Nd}_{2} \mathrm{Fe}_{14} \mathrm{~B}, \mathrm{Nd}_{2} \mathrm{Fe}_{17}$, and a small amount of $\mathrm{Nd}_{2} \mathrm{O}_{3}$ phases, and $\left(\mathrm{Nd}_{10.53} \mathrm{Fe}_{77.84} \mathrm{Co}_{11.63}\right)_{95} \mathrm{~B}_{5}$ powders mainly consist of $\alpha-\mathrm{Fe}$, a small amount of $\mathrm{Nd}_{2} \mathrm{Fe}_{14} \mathrm{~B}$ and $\mathrm{Nd}_{2} \mathrm{O}_{3}$ phases, and some crystal is turned into non-equilibrium organization. With the adding of $\mathrm{B}$ in $\left(\mathrm{Nd}_{10.53} \mathrm{Fe}_{77.84} \mathrm{Co}_{11.63}\right)_{100-x} \mathrm{~B}_{x}$ powders, the relative content of the $\alpha$-Fe phase increases, so the addition of $\mathrm{B}$ element has a great influence on the phase composition of the $\mathrm{Nd}_{10.53} \mathrm{Fe}_{77.84} \mathrm{Co}_{11.63}$ powders.

Fig. 2 shows the electromagnetism parameters of the $\mathrm{NdFeCoB}$ powders with different contents of B element in the frequency range of $2 \sim 18 \mathrm{GHz}$. As seen from Fig.2a and $2 \mathrm{~b}$, the $\mathrm{NdFeCo}$ powder has a high complex dielectric constant real part $\varepsilon^{\prime}$ and an imaginary part $\varepsilon^{\prime \prime}$ in $2 \sim 7 \mathrm{GHz}$ when $3 \%$ of the B element is added. But as it reaches $5 \%$, the complex dielectric constant real part $\varepsilon^{\prime}$ declines. The reason may be that a part of the crystal forms a non-equilibrium organization, and makes the electrical conductivity reduce, thus complex dielectric constant real part $\varepsilon^{\prime}$ value declining; at the same time, the freedom energy $\Delta E$ reduces, as a result the complex dielectric constant imaginary part $\varepsilon^{\prime \prime}$ rises. From Fig.2c it can be seen that with adding $3 \%$ of $\mathrm{B}$, the complex permeability real part $\mu^{\prime}$ and the imaginary part $\mu^{\prime \prime}$ of NdFeCo powder reduces obviously in $2 \sim 7 \mathrm{GHz}$, and this may be due to that a large number of $\mathrm{Nd}_{2} \mathrm{Fe}_{14} \mathrm{~B}$ phase precipitate and the relative

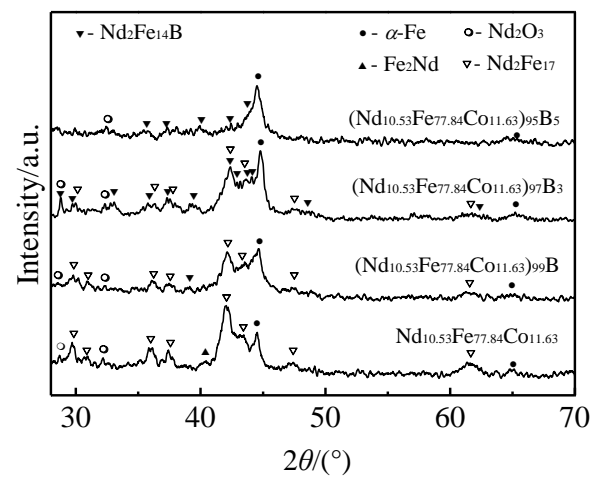

Fig.1 XRD patterns of $\left(\mathrm{Nd}_{10.53} \mathrm{Fe}_{77.84} \mathrm{Co}_{11.63}\right)_{100-x} \mathrm{~B} x(x=0,1,3,5)$ powders
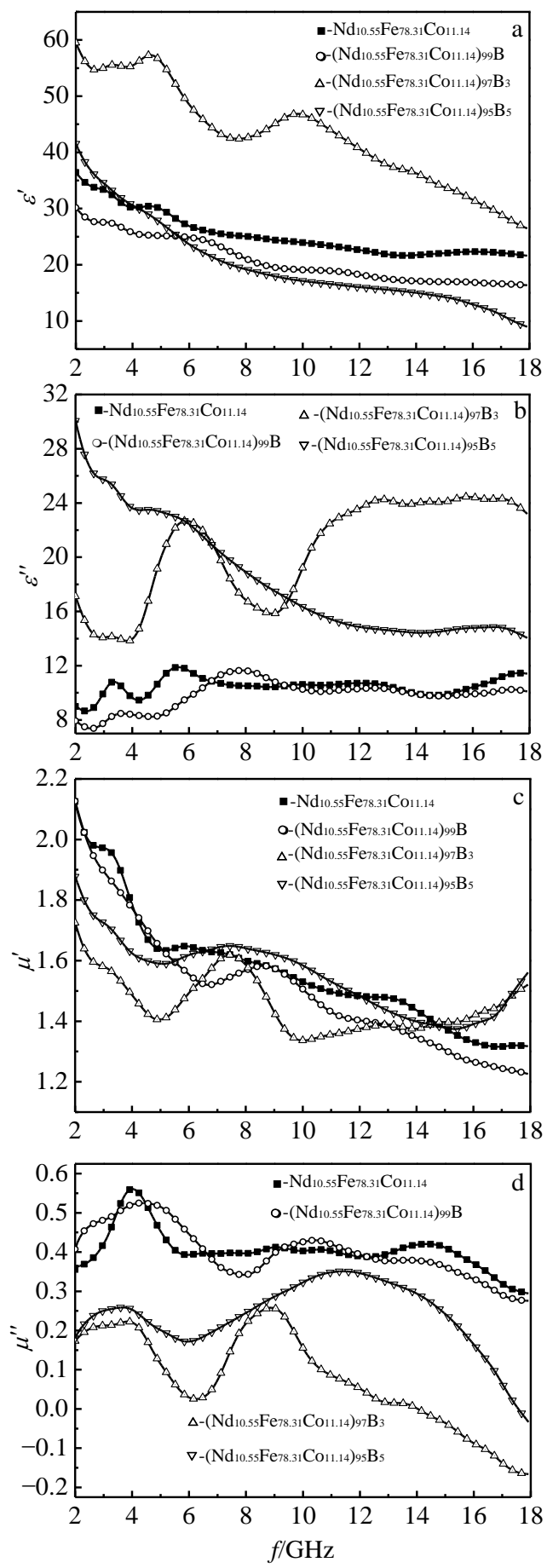

Fig.2 Electromagnetic parameters of $\left(\mathrm{Nd}_{10.55} \mathrm{Fe}_{78.31} \mathrm{Co}_{11.14}\right)_{100-x} \mathrm{~B}_{x}$ $(x=0,1,3,5)$ powders: (a) curves of $\varepsilon^{\prime}$ vs $f$, (b) curves of $\varepsilon^{\prime \prime}$ vs $f$, (c) curves of $\mu^{\prime}$ vs $f$, and (d) curves of $\mu^{\prime \prime}$ vs $f$

content of $\alpha-\mathrm{Fe}$ increases, which lead to the increase of the saturated magnetization $\left(M_{\mathrm{s}}\right)$, so the complex permeability (real part $\mu^{\prime}$ and imaginary part $\mu^{\prime \prime}$ ) reduces. But when the content of $\mathrm{B}$ reaches $5 \%$, the part of non-equilibrium organization is formed, and the saturated magnetization $\left(M_{\mathrm{s}}\right)$ of the powder is decreased; as a consequence the complex permeability (real part $\mu^{\prime}$ and imaginary part $\mu^{\prime \prime}$ ) $\operatorname{rises}^{[8]}$. 
According to the equivalent of transmission line theory, the reflection coefficient for coated single-layer electromagnetic microwave absorbing materials can be deduced as:

$$
R=20 \lg (\mid Z-1) /(Z+1) \mid
$$

where, $Z=\sqrt{\mu_{\mathrm{r}} / \varepsilon_{\mathrm{r}}} \tanh \left(j 2 \pi f d \sqrt{\mu_{\mathrm{r}} \varepsilon_{\mathrm{r}}} / c\right)$,

$\varepsilon_{\mathrm{r}}, \quad \mu_{\mathrm{r}}$ and $d$ are the relative dielectric constant, the relative permeability and the thickness of the absorbing material, respectively, $f$ for electromagnetic wave frequency, $c$ for electromagnetic wave in free space velocity, and $j$ for imaginary unit. The reflectivity $(R)$ of wave-absorbing materials is calculated by formula (1).

As shown in Fig.3, when $x=0,1,3,5$, the minimum reflectance and the absorption peak frequency are $-9.6 \mathrm{~dB}$ at $6.2 \mathrm{GHz},-9.4 \mathrm{~dB}$ at $6.5 \mathrm{GHz},-9.5 \mathrm{~dB}$ at $4.5 \mathrm{GHz}$ and $-6.2 \mathrm{~dB}$ at $6.8 \mathrm{GHz}$, respectively, when the thickness $d=1.8 \mathrm{~mm}$. The lowest absorption peak frequency is declined to $4.5 \mathrm{GHz}$ as the addition of $\mathrm{B}$ element is $3 \%$. The reason is that a great quantity of $\mathrm{Nd}_{2} \mathrm{Fe}_{14} \mathrm{~B}$ phase precipitate and the saturation magnetization $\left(M_{\mathrm{s}}\right)$ of $\mathrm{Nd}_{2} \mathrm{Fe}_{14} \mathrm{~B}$ phase is larger than that of $\mathrm{Nd}_{2} \mathrm{Fe}_{17}$ phase; at the same time the relative content of $\alpha$-Fe phase increased also makes the saturation magnetization $\left(M_{\mathrm{s}}\right)$ increase. According to $f_{r} \propto 1 / M_{\mathrm{S}}^{2}$, if the saturation magnetization $\left(M_{\mathrm{s}}\right)$ of the powder increases, the absorption peak frequency will decrease. When the content of B reaches $5 \%$, a lot of non-equilibrium organization are formed, and the saturation magnetization $\left(M_{\mathrm{s}}\right)$ of the powders reduces as a result of the absorption peak frequency rising to $6.8 \mathrm{GHz}$.

\subsection{Effects of $\mathbf{T b}$ on microwave absorption properties of NdFeCoB alloy}

The previous section discussed the impact of $\mathrm{B}$ on $\mathrm{NdFeCo}$ alloy and achieved some beneficial results. So this part is going to discuss the organization structure and microwave absorption characteristics changing by other rare earth elements replace $\mathrm{Nd}$. Through the comparative analysis, $\left(\mathrm{Nd}_{10.53} \mathrm{Fe}_{77.84} \mathrm{Co}_{11.63}\right)_{97} \mathrm{~B}_{3}$ was chosen as the research object, and the changing of organization structure and the absorbing properties were studied when using heavy rare earth $\mathrm{Tb}$ substitution of $\mathrm{Nd}$. $\left(\mathrm{Tb}_{10.53} \mathrm{Fe}_{77.84} \mathrm{Co}_{11.63}\right)_{97} \mathrm{~B}_{3}$ (mole fraction, \%) alloy was obtained as the same experiment

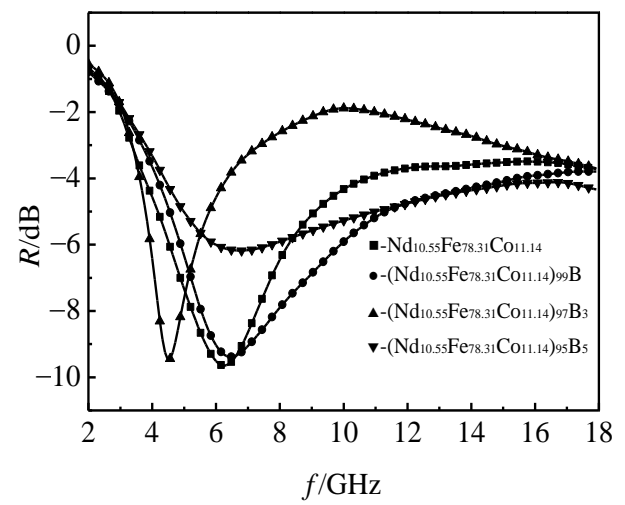

Fig.3 Reflectivity of $\left(\mathrm{Nd}_{10.55} \mathrm{Fe}_{78.31} \mathrm{Co}_{11.14}\right)_{100-x} \mathrm{~B}_{x}(x=0,1,3,5)$ powder method as previous.

Fig.4 is the XRD patterns of $\left(\mathrm{RE}_{10.53} \mathrm{Fe}_{77.84} \mathrm{Co}_{11.63}\right)_{97} \mathrm{~B}_{3}$ $(\mathrm{RE}=\mathrm{Nd}, \mathrm{Tb})$ powders, and the patterns show that $\left(\mathrm{RE}_{10.53} \mathrm{Fe}_{77.84} \mathrm{Co}_{11.63}\right){ }_{97} \mathrm{~B}_{3}$ powder is mainly composed of $\alpha-\mathrm{Fe}$, $\mathrm{RE}_{2} \mathrm{Fe}_{14} \mathrm{~B}, \mathrm{RE}_{2} \mathrm{Fe}_{17}$ and a small amount of $\mathrm{RE}_{2} \mathrm{O}_{3}$ phase.

Fig.5 shows the curves of the complex permittivity and the complex permeability versus frequency of the $\left(\mathrm{RE}_{10.53} \mathrm{Fe}_{77.84^{-}}\right.$ $\left.\mathrm{Co}_{11.63}\right)_{97} \mathrm{~B}_{3}(\mathrm{RE}=\mathrm{Nd}, \mathrm{Tb})$ powders in $2 \sim 18 \mathrm{GHz}$ band.

The graph shows that, $\left(\mathrm{Nd}_{10.53} \mathrm{Fe}_{77.84} \mathrm{Co}_{11.63}\right)_{97} \mathrm{~B}_{3}$ has higher complex dielectric constant real part $\varepsilon^{\prime}$, this may be mainly related to the fact that the electrical conductivity of $\mathrm{Nd}$ is greater than that of Tb's and the complex dielectric constant real part $\varepsilon^{\prime}$ is proportional to the square of the conductivity, thus complex dielectric constant real part $\varepsilon^{\prime}$ of the $\left(\mathrm{Nd}_{10.53} \mathrm{Fe}_{77.84-}\right.$ $\left.\mathrm{Co}_{11.63}\right)_{97} \mathrm{~B}_{3}$ powder is higher than that of the $\left(\mathrm{Tb}_{10.53} \mathrm{Fe}_{77.84}\right.$ $\left.\mathrm{Co}_{11.63}\right)_{97} \mathrm{~B}_{3}{ }^{\text {' }}{ }^{[8-11]} \cdot\left(\mathrm{Nd}_{10.53} \mathrm{Fe}_{77.84} \mathrm{Co}_{11.63}\right)_{97} \mathrm{~B}_{3}$ alloy has high complex dielectric constant imaginary part $\varepsilon^{\prime \prime}$ in the frequency band of $2 \sim 18 \mathrm{GHz}$. In band of $2 \sim 4 \mathrm{GHz},\left(\mathrm{Nd}_{10.53} \mathrm{Fe}_{77.84^{-}}\right.$ $\left.\mathrm{Co}_{11.63}\right)_{97} \mathrm{~B}_{3}$ has higher complex permeability (real part $\mu^{\prime}$ and imaginary part $\left.\mu^{\prime \prime}\right)$; along with the frequency increase, $\left(\mathrm{Nd}_{10.53} \mathrm{Fe}_{77.84} \mathrm{Co}_{11.63}\right)_{97} \mathrm{~B}_{3}$ complex permeability real part $\mu^{\prime}$ will be lower than that of $\left(\mathrm{Tb}_{10.53} \mathrm{Fe}_{77.84} \mathrm{Co}_{11.63}\right)_{97} \mathrm{~B}_{3}$; when frequency is more than about $6 \mathrm{GHz},\left(\mathrm{Nd}_{10.53} \mathrm{Fe}_{77.84} \mathrm{Co}_{11.63}\right)_{97} \mathrm{~B}_{3}$ complex permeability real part $\mu^{\prime}$ is again higher than that of $\left(\mathrm{Tb}_{10.53} \mathrm{Fe}_{77.84} \mathrm{Co}_{11.63}\right)_{97} \mathrm{~B}_{3}$ real part $\mu^{\prime}$; but when the frequency is higher than about $4 \mathrm{GHz},\left(\mathrm{Nd}_{10.53} \mathrm{Fe}_{77.84} \mathrm{Co}_{11.63}\right)_{97} \mathrm{~B}_{3}$ complex permeability imaginary part $\mu^{\prime \prime}$ will be lower than that of $\left(\mathrm{Tb}_{10.53} \mathrm{Fe}_{77.84} \mathrm{Co}_{11.63}\right)_{97} \mathrm{~B}_{3}$ complex permeability imaginary part $\mu^{\prime \prime}$.

According to the formula (1) the reflectivity of waveabsorbing materials can be calculated. As shown in Fig.6, the least reflectivity values of $\left(\mathrm{Nd}_{10.53} \mathrm{Fe}_{77.84} \mathrm{Co}_{11.63}\right)_{97} \mathrm{~B}_{3}$ and $\left(\mathrm{Tb}_{10.53} \mathrm{Fe}_{77.84} \mathrm{Co}_{11.63}\right)_{97} \mathrm{~B}_{3}$ powders are about $-9.5 \mathrm{~dB}$ at $4.5 \mathrm{GHz}$ and $-11 \mathrm{~dB}$ at $6.3 \mathrm{GHz}$ when the thickness $d=1.8 \mathrm{~mm}$. The main reason why the absorption peak frequency of $\left(\mathrm{Nd}_{10.53} \mathrm{Fe}_{77.84}\right.$ $\left.\mathrm{Co}_{11.63}\right)_{97} \mathrm{~B}_{3}$ powder is lower than that of $\left(\mathrm{Tb}_{10.53} \mathrm{Fe}_{77.84}\right.$ $\left.\mathrm{Co}_{11.63}\right)_{97} \mathrm{~B}_{3}$ powder is that the $M_{\mathrm{s}}$ of $\mathrm{Nd}_{2} \mathrm{Fe}_{14} \mathrm{~B}$ phase in $\left(\mathrm{Nd}_{10.53}\right.$ $\left.\mathrm{Fe}_{77.84} \mathrm{Co}_{11.63}\right)_{97} \mathrm{~B}_{3}$ powder is bigger than that of $\mathrm{Tb}_{2} \mathrm{Fe}_{14} \mathrm{~B}$ phase in $\left(\mathrm{Tb}_{10.53} \mathrm{Fe}_{77.84} \mathrm{Co}_{11.63}\right)_{97} \mathrm{~B}_{3}$ and according to the relationship

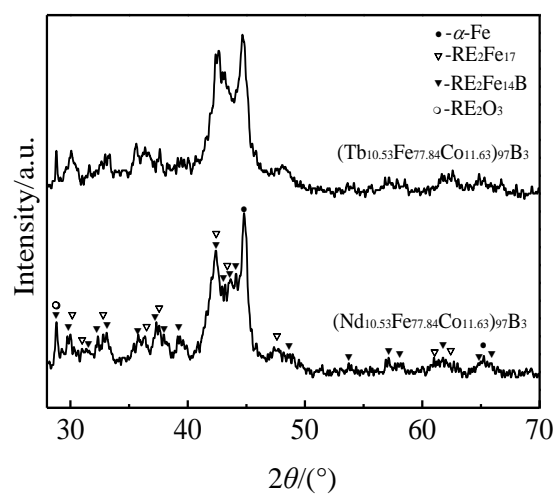

Fig.4 XRD patterns of ( $\left.\mathrm{RE}_{10.53} \mathrm{Fe}_{77.84} \mathrm{Co}_{11.63}\right){ }_{97} \mathrm{~B}_{3}(\mathrm{RE}=\mathrm{Nd}, \mathrm{Tb})$ powders 

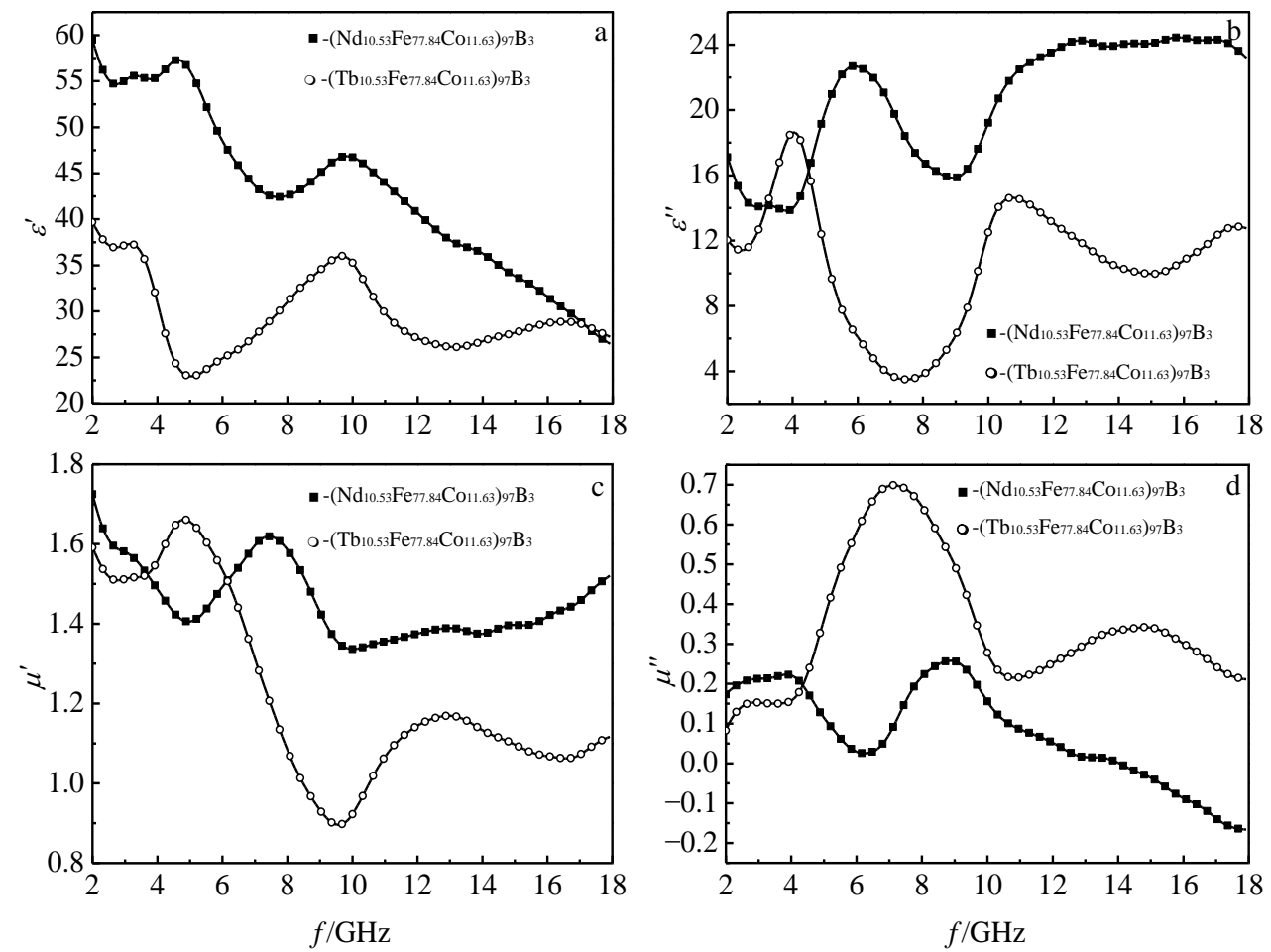

Fig.5 Electromagnetic parameters of $\left(\mathrm{RE}_{10.53} \mathrm{Fe}_{77.84} \mathrm{Co}_{11.63}\right)_{97} \mathrm{~B} 3(\mathrm{RE}=\mathrm{Nd}, \mathrm{Tb})$ powders: (a) curves of $\varepsilon^{\prime}$ vs $f$, (b) curves of $\varepsilon^{\prime \prime}$ vs $f$, (c) curves of $\mu^{\prime}$ vs $f$, and (d) curves of $\mu^{\prime \prime}$ vs $f$

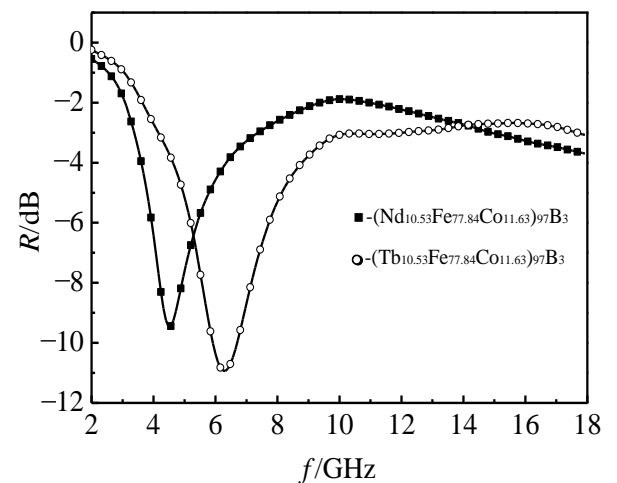

Fig.6 Reflectivity of $\left(\mathrm{RE}_{10.53} \mathrm{Fe}_{77.84} \mathrm{Co}_{11.63}\right)_{97} \mathrm{~B}_{3}(\mathrm{RE}=\mathrm{Nd}, \mathrm{Tb})$ powder

$f_{\mathrm{r}} \propto 1 / M_{\mathrm{s}}^{2}$, the absorption peak frequency of the $\left(\mathrm{Nd}_{10.53^{-}}\right.$ $\left.\mathrm{Fe}_{77.84} \mathrm{Co}_{11.63}\right)_{97} \mathrm{~B}_{3}$ powder will decrease ${ }^{[8-10]}$.

\section{Conclusions}

1) $\mathrm{Nd}_{2} \mathrm{Fe}_{14} \mathrm{~B}$ phase will precipitate when $\mathrm{B}$ is added into $\mathrm{Nd}_{10.53} \mathrm{Fe}_{77.84} \mathrm{Co}_{11.63}$ alloy, and the relative content of the $\alpha$-Fe phase increases. $\left(\mathrm{RE}_{10.53} \mathrm{Fe}_{77.84} \mathrm{Co}_{11.63}\right)_{97} \mathrm{~B}_{3}(\mathrm{RE}=\mathrm{Nd}, \mathrm{Tb})$ powders are mainly composed of $\alpha-\mathrm{Fe}, \mathrm{RE}_{2} \mathrm{Fe}_{14} \mathrm{~B}, \mathrm{RE}_{2} \mathrm{Fe}_{17}$ and a small amount of $\mathrm{RE}_{2} \mathrm{O}_{3}$ phases.

2) When $3 \%$ of $\mathrm{B}$ is added into $\mathrm{Nd}_{10.53} \mathrm{Fe}_{77.84} \mathrm{Co}_{11.63}$ alloy, the powder has a minimum of absorption peak frequency. When the coating thickness $d=1.8 \mathrm{~mm}$, the absorption peak value of the powders reaches $-9.5 \mathrm{~dB}$ at $4.5 \mathrm{GHz}$.

3) The absorption peaks of the $\left(\mathrm{Nd}_{10.53} \mathrm{Fe}_{77.84} \mathrm{Co}_{11.63}\right)_{97} \mathrm{~B}_{3}$ alloy powders shift towards high frequency when $\mathrm{Nd}$ is replaced by heavy rare earth $\mathrm{Tb}$.

\section{References}

1 Qiu Qin, Zhang Yanqing, Zhang Xiong. Electronic Components and Materials[J], 2009, 28(8): 78 (in Chinese)

2 Zhao Feng. Urban Environment \& Urban Ecology[J], 2011, 24(5): 39 (in Chinese)

3 Cui Benliang. Modern Electronics Technique[J], 2011, 34(20): 140 (in Chinese)

4 Zhou Kesheng, Liu Baogang, Huang Kelong et al. Journal of the Chinese Rare Earth Society[J], 2009, 27(1): 81

5 Chen Xianfu, Ye Jinwen, Liu Ying et al. Rare Metal Materials and Engineering[J], 2009, 38(4): 726 (in Chinese)

6 Feng Yongbao, Qiu Tai. Journal of Alloys and Compounds[J], 2012, $513: 455$

7 Meena R S, Sudeshna Bhattachrya, Ratnamala Chatterjee. Journal of Magnetism and Magnetic Materials[J], 2010, 322: 2908

8 Liao Shaobin. Ferromagnetism, Volume II[M]. Beijing: Science Press, 1988 (in Chinese)

9 Lv Ruitao, Kang Feiyu, Wei Jinquan et al. Journal of Inorganic Materials[J], 2008(1): 23 (in Chinese)

10 Zhou Shouzeng. Super Permanent Magnet-Fe-based Rare Earth Permanent Magnetic Materials (Second Edition)[M]. Beijing: 


\title{
RE(Nd, Tb)FeCoB 合金体系的微波吸收特性研究
}

\author{
潘顺康, 林培豪, 王 否, 刘 星, 胡士齐, 周怀营 \\ (桂林电子科技大学, 广西 桂林 541004)
}

\begin{abstract}
摘 要: 采用熔炼、高能球磨、微氧化热处理工艺, 制备RE(Nd, Tb)FeCoB粉体, 借助X射线衍射仪和网络矢量分析仪等, 研究不同 $\mathrm{B}$ 含 量的 $\mathrm{NdFeCo}$ 粉体组织结构和微波吸收特性, 以及用重稀土 $\mathrm{Tb}$ 取代 $\mathrm{NdFeCoB}$ 合金中的 $\mathrm{Nd}$ 后粉体的组织结构和微波吸收特性。结果发现: 在 $\mathrm{Nd}_{10.53} \mathrm{Fe}_{77.84} \mathrm{Co}_{11.63}$ 合金中加入 $\mathrm{B}$ 元素后会析出 $\mathrm{Nd}_{2} \mathrm{Fe}_{14} \mathrm{~B}$ 相, 而且, 粉体中 $\alpha$ - $\mathrm{Fe}$ 相的相对含量随着 $\mathrm{B}$ 元素含量的增加而增加; 用重稀土 $\mathrm{Tb}$ 取代 $\mathrm{NdFeCoB}$ 合金中的 $\mathrm{Nd}$ 后粉体主要由 $\alpha-\mathrm{Fe} 、 \mathrm{~Tb}_{2} \mathrm{Fe}_{14} \mathrm{~B} 、 \mathrm{~Tb}_{2} \mathrm{Fe}_{17}$ 以及少量的 $\mathrm{Tb}_{2} \mathrm{O}_{3}$ 相组成; $\left(\mathrm{Nd}_{10.53} \mathrm{Fe}{ }_{77.84} \mathrm{Co}_{11.63}\right)_{97} \mathrm{~B}_{3}$ 粉体具有最低的吸收 峰频率, 其反射率最小值和吸收峰频率分别为 $-9.5 \mathrm{~dB}$ 和 $4.5 \mathrm{GHz}$; 用重稀土 $\mathrm{Tb}$ 取代 $\left(\mathrm{Nd}_{10.53} \mathrm{Fe}_{77.84} \mathrm{Co}_{11.63}\right)_{97} \mathrm{~B} 3$ 合金中的 $\mathrm{Nd}$ 后, 粉体的吸收峰 频率升高到 $6.3 \mathrm{GHz}$, 但反射率最小值降低到 $-11 \mathrm{~dB}$ 。
\end{abstract}

关键词: $\mathrm{NdFeCoB}$; 微波吸收特性; 组织结构; 高能球磨

作者简介: 潘顺康, 男, 1973 年生, 博士, 教授, 桂林电子科技大学材料科学与工程学院, 广西 桂林 541004, 电话: 0773-2291434, E-mail: skpan88@163.com 